\title{
EXPANSÃO DA FRONTEIRA, MEGAPROJETOS DE INFRAESTRUTURA E INTEGRAÇÃ̃O SUL-AMERICANA
}

\author{
Edna Castro*
}

\begin{abstract}
As análises da relação entre políticas desenvolvimentistas e as dinâmicas socioterritoriais na Amazônia têm se voltado para a dimensão nacional. Este artigo procura revelar o aumento do interesse pela exploração dos recursos naturais da região para além de suas fronteiras políticas, tornando-se a Pan-Amazônia um espaco central na geopolítica brasileira. Os Planos de Aceleração do Crescimento (PAC I e II) e a Iniciativa para a Integração da Infraestrutura da América do Sul (IIRSA) assumem a mesma orientação de integração competitiva, adotando um modelo de modernização com base em megaprojetos de investimentos. A IIRSA, no âmbito sul-americano, como bloco regional, e o PAC, em âmbito nacional, são programas voltados para a logística de transporte, energia e comunicação. No plano continental, expressam dinâmicas socioterritoriais irreverersíveis e representam interesses comuns do Brasil e dos demais países, via modelo dominante de expansão da fronteira amazônica a partir dos anos 70 do século XX.

Palavras-chave: fronteira, políticas estatais, integração, megaprojetos, Pan-Amazônia.
\end{abstract}

\section{INTRODUÇÃO}

As estratégias governamentais e empresariais voltadas para a Amazônia, no Brasil, revelam o aumento do interesse pela exploração dos recursos naturais da região para além de suas fronteiras políticas. A Pan-Amazônia ocupa, assim, uma posição central na geopolítica brasileira. Por outro lado, os Estados nacionais vizinhos na região amazônica também se movimentam economicamente na expansão da fronteira, que é concebida como um espaço estratégico e um campo aberto à produção de commodities com a vantagem competitiva de facilidade de escoamento para o mercado mundial.

Empresas transnacionais e organismos multilaterais, como atores globais, têm pressionado a esfera política para modificar dispositivos legais e instituições a fim de adequá-los à

* Doutora em Sociologia. Professora da Universidade Federal do Pará (UFPA). Coordenadora do Grupo de Pesquisa Trabalho, Empresas e Transformações Sociais, do Diretório do CNPq.

Campus da UFPA. Av. Augusto Correa, n.01. Guamá. Cep: 66075-090. Belém - Pará - Brasil. edna.mrcastro@gmail.com nova economia. Os Estados nacionais continuam a ter papel importante na regulação social, política e econômica, e permanecem protagonistas, mas sob uma lógica liberalizante do capital, tendo, inclusive, sucumbido a certos acordos de agências reguladores internacionais e penalizado as relações de trabalho, como se observa na atual crise dos países da Comunidade Econômica Europeia (CEE). Nesse quadro da economia mundial, a competição intercorporações e inter-redes tende a intensificarse. Empresas impulsionadas pela concorrência procuram continuamente reestruturar-se, buscando formas de reduzir custos e visando demandas futuras (Castro, 2004). A articulação de grandes empresas industriais e financeiras que funcionam em rede resulta também da unificação, nos países mais avançados, dos mercados financeiro, cambial, de títulos e valores (Chesnais, 1996).

Neste artigo, procuramos demonstrar a associação entre as políticas nacionais brasileiras e os projetos de intervenção da Iniciativa para a Integração da Infraestrutura da América do Sul (IIRSA). Os Planos de Aceleração do Crescimento (PAC I e II) e a IIRSA assumem a mesma orienta- 
ção de integração competitiva, adotando um modelo de modernização com base em megaprojetos de investimentos. Ambos estão articulados pela concepção de eixos de integração e desenvolvimento. A IIRSA, no âmbito sul-americano, como bloco regional, e o PAC, em âmbito nacional, são programas voltados para a logística de transporte, energia $\mathrm{e}$ comunicação. No plano continental, essa logística representa interesses comuns do Brasil e dos demais países nos projetos de infraestrutura. Ela reedita o modelo de desenvolvimento que orientou a expansão da fronteira amazônica a partir dos anos 70 do século XX e provocou conflitos socioterritoriais que envolveram diferentes atores locais e intensificaram a exploração de recursos naturais e o desmatamento. A tendência observada na pesquisa em curso $^{1}$ é a irreversibilidade dessas dinâmicas, pois a Pan-Amazônia tornou-se um grande palco de ações governamentais e empresariais, é entendida como central não apenas para o Brasil, mas também para a América do Sul. Populações locais, com suas práticas sociais e saberes relativos ao território, têm produzido leituras desse processo, a partir de movimentos sociais e étnicos que revelam novos processos de dominação incorporados ao modo de implantação dos projetos de infraestrutura eàs práticas de agentes que violam direitos sociais e étnicos, como o resultado da desterritorialização que atinge grupos de população tradicional, na extensão pan-amazônica.

\section{IIRSA, ANTECEDENTES E RELAÇÃO COM OS EIXOS DE DESENVOLVIMENTO DO PLANEJAMENTO BRASILEIRO}

A Associação Latino-Americana de Livre Comércio, criada em 1960, já visava a eliminar as barreiras ao comércio entre os Estados, mas não conseguiu impor-se. Em 1969, os países criaram o Pacto Andino, fundado em um modelo de planejamento do desenvolvimento com alocação de investimentos. Retomando princípios presentes na matriz da Associação Latino-Americana de

${ }^{1}$ Pesquisa do CNPq, bolsa de produtividade.
Integração (ALADI) a partir de negociações entre o Brasil e a Argentina, o Mercosul nasce com o mesmo objetivo de integração de mercados, "enquadrado na concepção do Consenso de Washington do livre comércio como instrumento único e suficiente para a promoção do desenvolvimento, redução das desigualdades sociais e geração de empregos, na melhor tradição das Escolas de Manchester e deChicago" (Guimarães, 2008, p.32). Em 1994, os Estados Unidos lançaram, no contexto da Cúpula das Américas, o projeto de uma Área de Livre Comércio das Américas (ALCA), apostando no livre comércio, que se "configuraria como um processo unificador do território formado por todos os países sul-americanos, seguindo orientações do Fundo Monetário Internacional (FMI) e da Organização Mundial do Comércio (OMC)" (2008, p.36).

Na Primeira Cúpula dos Presidentes da América do Sul, realizada em 1999, foi assinado um protocolo de intenções e de cooperação entre 12 países pan-americanos, institucionalizando a IIRSA, que pretendia traçar novas bases para uma regionalização no continente. Em setembro de 2000, em Brasília, doze presidentes dos Estados nacionais da América do Sul consolidaram a IIRSA e reconheceram, como questão principal para direcionar investimentos, a infraestrutura física instalada na região, pois sua fragmentação impedia o crescimento do mercado interno sulamericano e a abertura de novos mercados. Em julho de 2002, a Cúpula de Estados reúne-se em Guayaquil (Equador) para decidir sobre o projeto de infraestrutura. Em dezembro de 2004, a IIRSA é finalmente aprovada na cidade de Cuzco, no Peru, como estratégia principal de investimentos. Outras organizações têm-se associado nesse processo de formulação de novas diretrizes geopolíticas, do espaço andino ao amazônico. Para os governos sul-americanos, a IIRSA representa, para seus países, a possibilidade de tornarem-se mais competitivos no mercado internacional e, dessa forma, usufruírem de condições vantajosas no processo de globalização. Tal perspectiva também constitui um dos fundamen- 
tos da política internacional do governo brasileiro presente na proposta do Plano Plurianual 20042007. Em ambos os casos, trata-se da integração sul-americana a partir de sua integração física.

O conceito de integração, nessa perspectiva, pressupõe necessariamente ações estatais, uma esfera supranacional. Não são mencionados nem valorizados os processos de integração existentes há séculos nas fronteiras, marcados por populações que ali vivem e têm suas práticas ancoradas em uma dada ordem social e econômica. As esferas supranacionais que concebem a IIRSA consideram-na como uma

estrutura sistêmica e de integração, cuja logística tem por base o desenvolvimento da telecomunicação, do transporte e de energia, a fim de criar as condições para a sua integração econômica, política, social, cultural (IIRSA, 2004, p.7; 2011, p.23).

A integração da América do Sul constitui um dos objetivos principais das estratégias políticas e econômicas dos governos sul-americanos, estando no centro da política externa brasileira. A noção de Eixos Nacionais de Integração constituiu a estratégia maior para estreitar as relações com os países da América do Sul, na grande fronteira política, conformando um bloco econômico com maior poder de fogo, dada a organização em curso de outros nichos de mercado, nos diferentes continentes. Certamente, a integração geográfica por meio da construção de vias de comunicação terrestres seria o primeiro passo desse processo, pois, como analisa Guimarães (2008, p.9), a

política externa não poderá ser eficaz se não estiver ancorada na política brasileira na América do Sul. As características da situação geopolítica do Brasil, isto é, seu território, sua localização geográfica, sua população, suas fronteiras, sua economia, assim como a conjuntura e a estrutura do sistema mundial, tornam a prioridade sulamericana uma realidade essencial.

Por outro lado, o governo brasileiro tem defendido seu projeto desenvolvimentista e testado, nas relações internacionais, sua capacidade de negociar novos mercados no espaço sul-america- no. Não se trata apenas de discursos diplomáticos, mas de ações concretas efetivadas por meio de novas regulamentações e acordos de cooperação que apontam na direção de financiamentos e projetos de infraestrutura e permitam uma ligação multimodal entre os países. Observa-se a busca de eficácia simbólica atribuida às novas estruturas de poder, que estão associadas, em última análise, a estratégias do campo político (Bourdieu, 1989). O Brasil, por intermédio de suas instituições, como o Banco Nacional de Desenvolvimento Econômico e Social (BNDES), tornou-se um financiador de projetos em inúmeros fronteiras nacionais de países da IIRSA.

\section{A "visão estratégica" do planejamento nacio- nal e a concepção do PAC I e II}

O conceito de território foi retomado pela área do planejamento no final dos anos 90 do século XX, como possibilidade de inovação nas formas de intervenção pública, associada à noção de participação. O Ministério do Planejamento, Orçamento e Gestão, em documento intitulado Estudo da dimensão territorial para o planejamento (volume I: Sumário Executivo) (Brasil. Ministério do Planejamento, 2008a), informa a metodologia adotada, bem como justifica o uso da noção de território e de controle territorial, o que seria essencial para obter resultados nas estratégias de desenvolvimento nacional, em situação de alta concorrência e de economia fortemente globalizada e competitiva. Essa noção foi redefinida a partir de mudanças na produção capitalista que tenderam a comprimir espaço e tempo (Harvey, 1998 p.79) e funcionar sob uma lógica de deslocalização. O território é importante, porém dentro de outra configuração, na qual o espaço é desconectado de valores, lugares, tradições e passa a ser regido por relações econômicas e políticas, protagonizadas sobretudo por agentes do mercado. Por isso, o rompimento com as raízes, com as heranças culturais e com as territorialidades passa a constituir um desafio para empresas, corporações 
e mesmo para o Estado, em suas políticas que favorecem o mercado, contrariando interesses locais que funcionam com base em uma outra concepção de tempo e espaço, ancorada no mundo da vida, na cultura, e, portanto, não mediatizada pelo mercado. A noção de território adotada pelas políticas governamentais contraria a noção de território e de territorialidade dos grupos que vivem na Amazônia, regidos por outra ordem social de tempo e espaço. Para esses grupos, o território é um "espaço sobre o qual um certo grupo garante aos seus membros direitos estáveis de acesso, de uso e de controle sobre os recursos e sua disponibilidade no tempo.” (Castro, 1997, p.105).

Os Eixos Nacionais de Integração e Desenvolvimento constituíram a matriz do planejamento e da intervenção dos últimos governos brasileiros e pressupõem uma visão geográfica de domínio e controle dos territórios. Os Eixos estão presentes no Plano Brasil em Ação (1996-1999), no Avança Brasil (2000-2003) e igualmente nos Planos Plurianuais de 1996-1999, 2000-2003 e 20042007, que revelam as prioridades espaciais do Estado. ${ }^{2}$ A partir de 2007, o planejamento federal passa a adotar uma visão de futuro denominada visão estratégica nacional, que pretende tornar-se uma premissa balisadora, orientar os investimentos estratégicos e projetar metas para o desenvolvimento a médio e longo prazos (Brasil.Ministério do Planejamento, 2008b). Essa visão estratégica nacional recobre programas, políticas e projetos que o Estado considera importantes para o desenvolvimento econômico do país. Assim, o Programa de Aceleração do Crescimento (PAC I), lançado em 2007, prossegue o alinhamento da política econômica. Para sua consecução, os instrumentos normativos e as prioridades deveriam, em princípio, estar articulados e adaptados de forma a ori-

${ }^{2}$ Os Eixos seguem um perfil de intervenção consagrado em décadas anteriores por meio dos polos de desenvolvimento, de regionalização ou dos grandes projetos geopoliticamente referenciados. Os Eixos previstos para o Plano 2004-2007 consideraram quatro variáveis e seus indicadores; até aí, não há realmente muita diferença em relação ao planejamento estratégico dos anos 60 ou 70, como se pode observar nos seguintes recursos de planejamento: rede multimodal de transportes, hierarquia funcional das cidades, identificação dos centros dinâmicos e dos ecossistemas. entar a intervenção na economia e no território. Ao PAC I estão associados: a Política de Desenvolvimento Produtivo (PDP), a Política Nacional de Logística e Transporte (PNLT), a Política Nacional de Transporte Hidroviário (PNTH), o Plano Nacional de Viação, o Plano Nacional de Energia 2030 e a Matriz Energética Nacional 2030, a Política Nacional de Aviação Civil (PNAC), o Plano Hidroviário Estratégico, o Plano Nacional de Mineração e o Plano de Ordenamento Territorial. Todos esses dispositivos vinculam-se aos mesmos eixos de desenvolvimento e à mesma visão estratégica, unindo macropolíticas a políticas setoriais, regionais e territoriais.

O PAC constitui, assim, uma macropolítica de crescimento econômico, uma estratégia do Estado e dos setores econômicos. A estrutura do PAC I (2007-2010) dividia-se em três eixos: Logística, Energética e Social e Urbana. No PAC 2, são seis eixos: PAC Cidade Melhor (enfrentar os principais desafios das grandes aglomerações urbanas, propiciando melhor qualidade de vida); PAC Comunidade Cidadã (garantir a presença do Estado nos bairros populares, aumentando a cobertura de serviços); PAC Minha Casa, Minha Vida (reduzir o déficit habitacional, dinamizando o setor de construção civil e gerando trabalho e renda); PAC Água e Luz para Todos (universalizar o acesso à água e à energia elétrica); PAC Transportes (consolidar e ampliar a rede logística, interligando os diversos modais, garantindo qualidade e segurança); PAC Energia (garantir a segurança do suprimento a partir de uma matriz energética e desenvolver as descobertas no Pré-Sal) (Brasil, 2011, p.31).

Uma primeira observação é que o PAC orienta um modelo de crescimento econômico, e não somente um plano de desenvolvimento stricto sensu. Ora, trata-se de um modelo há décadas criticado pelo seu reducionismo e pela sua ineficácia social e ambiental. Ele retoma a experiência do planejamento da década de 70 para a Amazônia e projeta, para essa região, uma modernização com base na produção de commodities dos setores pecuária, madeira, grãos, minérios e energia. 
Efetivamente, os megaprojetos hidrelétricos, de transporte e comunicação formam a base dos investimentos do PAC I e II no Brasil, tanto quanto os projetos do IIRSA na América do Sul. Essas estratégias baseiam-se no mercado global, nos padrões de competitividade e de produtividade que seguem lógicas econômicas e nos processos de produção que obedecem a agendas de diferentes empresas em redes de clientes, de fornecedores ou consumidores. A questão em jogo não é necessariamente o mercado nacional, embora ele esteja potencialmente em expansão e seja fundamental na regulação de custos, ultrapassando inclusive o mercado representado pelo conjunto dos países da América do Sul. A mira está nos países asiáticos, razão da insistência em saídas pelo Pacífico e pelo Atlântico, para além América do Sul. Esse mercado externo é altamente competitivo e regula os tempos e usos do território. Daí uma preocupação constante com os corredores de transporte, para reduzir os custos e, consequentemente, aumentar a rentabilidade e a competitividade nacional e global.

$\mathrm{O}$ avanço do grande capital nacional e internacional, representado pelas grandes empresas apoiadas pelo PAC I e PAC II, busca acelerar o crescimento da economia. Somente para o período de 2007 a 2010, o PAC previa investimentos no montante de R $\$ 503,9$ bilhões. Com essas obras, o Estado assegura a implantação de grandes grupos empresariais para os mesmos setores: mineração, pecuária, exploração madeireira e agricultura mecanizada. Todos eles são produtos de commodities.

\section{Integração da América do Sul e da Pan-Ama- zônia}

O Estado brasileiro está cada vez mais interessado nas fronteiras políticas. O pensamento geopolítico brasileiro, cujas matrizes são encontradas no PAC I e II, considera a região amazônica extraordinariamente rica em fronteiras e, num zoom imaginário, percorre o olhar do Nordeste ao Noro- este, do Oeste ao Sudeste, conferindo a fronteira e as oportunidades de negócios. O Brasil faz fronteira geográfica com 11 países da América do Sul, e mais de 2/3 dessa faixa de fronteira estão na região amazônica. Trata-se de um olhar simplificador sobre o sentido das relações políticas entre países com situações de fortes assimetrias. Justamente por isso, é fundamental entender as injunções desse processo, pois as políticas de integração revelam o poder de decisão do Brasil e o motivo de contendas diplomáticas recentes entre os países. É uma postura defendida nos meios políticos, técnicos e empresariais, que concebem o Brasil e seu futuro segundo uma visão estratégica e de dominação.

Os projetos da IIRSA estruturam-se em Eixos de Integração. São, ao todo, 10 Eixos que recobrem o continente de norte a sul, de leste a oeste. Três deles estão direcionados para a PanAmazôna e atendem ao interesse pelas vias de transporte - estradas, ferrovias, rios - do Atlântico ao Pacífico. Este artigo refere-se exclusivamente a três eixos, os do norte-oeste. ${ }^{3}$ No eixo do Amazonas (Brasil, Colômbia, Equador e Peru), encontram-se os projetos de duas hidrelétricas no rio Madeira, no Brasil (Jirau e Santo Antônio), e, na mesma bacia, estão previstas duas hidrelétricas na Bolívia e quatro no Peru, o que tem sido objeto de contestação por parte de populações locais que sentem seus direitos territoriais e identitários ameaçados nos três países. O eixo Escudo Guianês, denominação dada à região formada pela parte oriental da Venezuela, pelo extremo norte do Brasil (estados de Amapá e Roraima), pelas Guianas e pelo Suriname, elege cidades como referência na logística de transporte e serviços: Manaus, Caracas, Macapá, Georgetown, Paramaribo, Boa Vista,

Caiena, Santa Elena de Uiarén, Ciudad Bolivar e Ciudad Guayana. O eixo Brasil, Peru e Bolívia, com saída para o Pacífico, compreende uma enorme extensão territorial - sete departamentos da região

${ }^{3}$ O objetivo principal dos projetos da IIRSA é interligar os
sistemas modais desses países. Para o Brasil, estão
projetadas inúmeras centrais de transporte, partindo dos
portos de Ilo e Matarani no Pacífico, por exemplo, mas
também de Tumaco (na Colômbia), Esmeraldas (no Equa-
dor) e Paita (no Peru), que serão ligados aos portos brasi-
leiros de Manaus, Belém e Macapá. 
sul do Peru (Tacna, Moquegua, Arequipa, Apurimac, Cuzco, Puno e Madre de Deus), dois departamentos amazônicos da Bolívia (Pando e Beni) e quatro estados do Brasil (Acre, Rondônia, Amazonas e Mato Grosso) (BRASIL. Ministério do Planejamento, 2008a, p. 12) ${ }^{4}$ - e toma as vias de transporte como estruturantes do território.

Construídos na mesma perspectiva, os projetos do PAC e da IIRSA articulam-se e parecem coordenados e complementares, como se observa na consulta feita aos dados oficiais das instâncias sul-americanas de planejamento. As informações contidas no Quadro 2 mostam uma coerência formal nos projetos nacionais e internacionais.

O PAC projetou a pavimentação das rodovias Transamazônica, Cuiabá-Santarém (BR-163) e Porto Velho-Manaus (BR-394), que, aparentemente, estão distantes da fronteira nacional, se consi- porte interno no país aos projetos na fronteira com outros países. É o caso das rodovias que ligam Rondônia e Acre à Bolívia e ao Peru, ligadas definitivamente ao sistema de transporte fluvial, intermodal, do rio Amazonas/Solimões. É o caso da ponte sobre o rio Oiapoque, ligando o Brasil à Guiana Francesa e abrindo, a partir dela, outra saída para o Caribe. É ainda o caso da melhoria das estradas Manaus-Caracas (BR-432), Boa Vista-Santa Elena de Uiarém, também na fronteira com a Venezuela, e da rodovia Boa Vista-BonfimLethem-Linden-Georgetown, na fronteira com a Guiana. Cabe ressaltar ainda que estão em curso os projetos de construção e de melhorias dos terminais fluviais na Amazônia, que vinculam os projetos do PAC aos do PNLT e aos da IIRSA. Entende-se, nessa ótica, que se está diante de um movimento ao mesmo tempo rápido e simultâneo,

Quadro 1 - Investimentos da IIRSA nos Eixos do Amazonas, do Escudo das Guianas e do Peru-Brasil-Bolívia

\begin{tabular}{|c|c|c|}
\hline $\begin{array}{l}\text { Eixos de Integração na Pan } \\
\text { Amazônia }\end{array}$ & $\begin{array}{c}\text { Recursos alocados } \\
\mathrm{R} \$ \\
\end{array}$ & Conexões pretendidas e áreas de interesse \\
\hline Eixo Amazonas & 91.323 .220 .000 & $\begin{array}{l}\text { Acesso à hidrovia do Solimões-Amazonas } \\
\text { Acesso à hidrovia do Ucalyali } \\
\text { Rede de hidrovias amazônicas }\end{array}$ \\
\hline Eixo do Escudo da Guiana & 1.098 .000 .000 & $\begin{array}{l}\text { Interconexão Guiana-Suriname-Guiana Francesa - Brasil } \\
\text { Interconexão Venezuela - Brasil } \\
\text { Interconexão Brasil - Guiana }\end{array}$ \\
\hline \multirow[b]{2}{*}{ Eixo Peru - Brasil- Bolívia } & 835.592 .293 .930 & $\begin{array}{l}\text { Corredor Porto Velho - Rio Branco - Assis - porto } \\
\text { Maldonado-Cusco/Juliaca - portos do Pacífico } \\
\text { (Brasil, Peru) }\end{array}$ \\
\hline & & $\begin{array}{l}\text { Corredor Rio Branco- Cobija- Riberalta-Yucumo- } \\
\text { La Paz (Brasil, Bolívia) } \\
\text { Corredor fluvial do rio Madeira- Madre de Dios- } \\
\text { Beni (Brasil, Peru) }\end{array}$ \\
\hline
\end{tabular}

Fonte: IIRSA (2011).

derada a dimensão geográfica. No entanto, a análise de fluxos vincula esses grandes eixos de trans-

${ }^{4}$ As três principais saídas para o Pacífico apontadas nos projetos da IIRSA, que receberão investimentos seus ou de governos nacionais, são: a) saída do Brasil pelo PeruPorto Velho até Cruzeiro do Sul e daí ao Peru; b) saída do Brasil pelo Peru: corredor com o trajeto Porto Velho-Rio Branco (BR-364); Assis Brasil (rodovia); Puerto Maldonado-Juliaca-portos de Puno/Ilo ou Matarani); c) saída do Brasil pela Bolívia: Porto Velho-Abunã-Guajará Mirim (BR-364 e BR-317); Guayaramerín-Caracnavi-La Paz, de estrada; La Paz a Patacamaya-Tambo Quemado-portos de Arica e Iquique. em múltiplas direções, o que se configura em um novo espaço de fluxos.

No Brasil, o conjunto de instrumentos que compõem o sistema de planejamento tem reforçado projetos para os estados com grandes faixas de fronteira - como Rondônia, Acre, Roraima e Amazonas -, não apenas por razões de defesa territorial e segurança, mas também por razões de ordem econômica. Amplia-se, assim, a intervenção do Estado e o 
Quadro 2 - Coherencia de los Proyectos de la AIC con la Planificación Territorial Indicativa. Evolucion de Estado 2005-2010

\begin{tabular}{|c|c|c|c|c|c|c|c|}
\hline $\mathrm{N}^{\circ}$ & Eje y Nombre del Proyecto & $\begin{array}{l}\text { Países } \\
\text { Inversores/ } \\
\text { Beneficiarios }^{1}\end{array}$ & $\begin{array}{l}\text { Ancla }^{2} / \\
\text { Asociado } \\
\text { a Ancla }^{3}\end{array}$ & $\begin{array}{l}\mathrm{N}^{\circ} \text { de } \\
\text { Grupo }\end{array}$ & $\begin{array}{l}\text { Tipo de } \\
\text { Grupo } 5\end{array}$ & $\begin{array}{l}\text { Estado a } \\
\text { julio } \\
2005^{6}\end{array}$ & $\begin{array}{l}\text { Es tado a } \\
\text { julio } \\
2010^{7}\end{array}$ \\
\hline \multicolumn{8}{|c|}{ EJE DEL AMAZONAS } \\
\hline 20 & $\begin{array}{l}\text { Corredor Vial Tumaco-Pasto - } \\
\text { Mocoa-Puerto Asis }\end{array}$ & $\mathrm{CO}$ & Ancla & G1 & Emergente & $\begin{array}{l}\text { Pre- } \\
\text { ejecución }\end{array}$ & Ejecución \\
\hline 21 & $\begin{array}{l}\text { Carretera Paita - Tarapoto - } \\
\text { Yurimaguas, Puertos y Centros } \\
\text { Logísticos }\end{array}$ & $\mathrm{PE}(\mathrm{BR})$ & $\begin{array}{l}\text { Ancla y } \\
\text { Asociado }\end{array}$ & G3 & Emergente & Ejecución & Ejecución \\
\hline 22 & $\begin{array}{l}\text { Carretera Lima - Tingo María - } \\
\text { Pucallpa, Puertos y Centros } \\
\text { Logísticos }\end{array}$ & $\mathrm{PE}(\mathrm{BR})$ & $\begin{array}{l}\text { Ancla y } \\
\text { Asociado }\end{array}$ & G4 & Consolidado & Ejecución & Ejecución \\
\hline 23 & Puerto Francisco de Orellana & EC & Ancla & G2 & Emergente & Perfil & $\begin{array}{l}\text { Pre- } \\
\text { ejecución }\end{array}$ \\
\hline \multicolumn{8}{|c|}{ EJE PERÚ-BRASIL -BOLíVIA } \\
\hline 24 & $\begin{array}{l}\text { Pavimentación Iñapari -Puerto } \\
\text { Maldonado-Inambari, } \\
\text { Inambari-Juliaca/Inambari - } \\
\text { Cusco }\end{array}$ & $\mathrm{PE}(\mathrm{BR})$ & Ancla & G1 & Emergente & $\begin{array}{l}\text { Pre- } \\
\text { ejecución }\end{array}$ & Ejecución \\
\hline 25 & Puente sob re el Rio Acre & $\mathrm{BR}-\mathrm{PE}$ & Asociado & G1 & Emergente & Ejecución & Concluido \\
\hline \multicolumn{8}{|c|}{ EJE DEL ESCUDO GUAYANÉS } \\
\hline 26 & $\begin{array}{l}\text { Carretera Boa Vista -Bonfim - } \\
\text { Lethem-Georgetown } \\
\left(1^{\circ} \text { Etapa:Estudios }\right)\end{array}$ & $\mathrm{GY}-\mathrm{BR}$ & Ancla & G2 & Emergente & $\begin{array}{l}\text { Pre- } \\
\text { ejecución }\end{array}$ & Ejecución \\
\hline 27 & Puente sobr e el Rio Takutu & $\mathrm{GY}-\mathrm{BR}$ & Asociado & G2 & Emergente & Ejecución & Concluido \\
\hline 28 & $\begin{array}{l}\text { Carretera Venezuela (Ciudad } \\
\text { Guayana) -Guyana } \\
\text { (Georgetown) -Suriname } \\
\text { (Paramaribo) }\left(1^{\circ} \text { Etapa) }\right.\end{array}$ & $\mathrm{VE}-\mathrm{GY}-\mathrm{SU}$ & Ancla & G3 & Emergente & Perfil & Perfil \\
\hline 29 & $\begin{array}{l}\text { Mejorias en la Via Nieuw } \\
\text { Nickerie-Paramaribo - Albina } \\
\text { y Cruce Internacional sobre el } \\
\text { Rio Marowijne }\end{array}$ & SU-GY & $\begin{array}{l}\text { Ancla y } \\
\text { Asociado }\end{array}$ & G4 & Emergente & Perfil & Ejecución \\
\hline
\end{tabular}

Fonte: IIRSA (2011)

ordenamento dos espaços amazônicos. Trata-se de faz presente estrategicamente com o peso do um projeto, acima de tudo, de grandes impactos so- BNDES, que financia projetos nos diferentes países, ciais e ambientais, por ser amplo, totalizante, e de empresas como a Petrobras e a Vale, que têm hegemônico e autoritário. plantas de exploração de recursos naturais - minéri-

Por isso, o Programa de Aceleração do os, petróleo-em quase todos os países sul-americaCrescimento, PAC I e II, precisa ser entendido nos. Instituições supranacionais também participam na sua relação com o projeto de integração sul- do processo de mercantilização e financeirização da americana. Ele tem a mesma matriz teórica e economia, no PAC I e II e na IIRSA. As seguintes ideológica da IIRSA. Baseia-se, também, na mes- organizações também consideram a infraestrutura ma matriz conceitual, por reproduzir a ideia de fundamental para o mercado: Banco Mundial (BM), integração com os países vizinhos. Não é uma es- Fundo Monetário Internacional (FMI), Banco tratégia tão somente nacional, mas continental, Interamericano de Desenvolvimento (BID), Comisvoltada para o mercado mundial, embora o papel são Europeia (CE), Organização de Cooperação e de principal seja desempenhado pelo Brasil, que se Desenvolvimento Econômicos (OCDE), Comissão 
Econômica para a América Latina e o Caribe (CEPAL), Organização Marítima Internacional (IMO). Como mostram Boyer (2006, p.51-52) e Chesnais (1996, p.80-86), essas instituições têm dispositivos de regulação, acordos e convenções.

\section{PAC E IRSA: o papel do transporte no espa- ço global de fluxos}

As mudanças verificadas na economia mundial, com a reestruturação da produção e dos meios de comércio e com a crescente financeirização e globalização, alteraram o padrão tecnológico e o de gestão, importantes para os fluxos de mercadorias, de serviços e, sobretudo, de informações. Assim, inovações tecnológicas adotadas pela engenharia naval foram significativas para alterar o porte e a capacidade dos navios de longo curso, o perfil das grandes transportadores de contêineres e os processos de gestão, reduzindo, portanto, o tempo de navegação e ampliando o fluxo de negócios. Isso levou a uma surpreendente dissociação do tempo e do espaço e, ao mesmo tempo, à compressão do tempo e à relativização dos espaços de produção, comércio e consumo.

Fluxos mais rápidos de transporte devido às tecnologias empregadas, menor tempo nos portos, mais capacidade em volume de mercadorias e, consequentemente, o aumento do número de viagens levaram à redução dos custos médios por tonelada transportada. Esse tipo de transporte tem crescido no mundo e feito pressão para a liberação de impasses alfandegários, evidenciando processos de desregulamentação de dispositivos legais, encontrados em diversos países. Até o último quartel do século XX, não seria economicamente viável, para o fluxo de acumulação, transportar quantidades imensas de mercadorias em fluxos contínuos. Hoje, produtos da indústria automobilística, carros, tratores, peças de reposição circulam com regularidade da Coreia do Sul e da China para o porto de Santos, e os fluxos funcionam no ritmo da econo-

mia globalizada, o que produz, no mercado, um efeito de estabilidade institucional, com concessionárias instaladas, mecanismos legais operativos e expansão de mercado. Países imensos como o Brasil, em todas suas regiões, são abastecidos com um padrão de comércio relativamente compatível com concorrentes instalados no parque automobilístico brasileiro desde o século XX.

Assim, a logística de transporte passou a ser integrada aos fluxos de produção por meio de modelos sofisticados de aplicação just-in-time e de flexibilização de processos e produtos, com base em sincronização de tempos entre portos internacionais, nacionais e regionais, independentemente de países e continentes, de distâncias e produtos. Isso se tornou possível em função da reestruturação da gestão, com a redução do tempo de armazenamento de mercadorias, a rapidez de fluxos, o direcionamento de fornecedores e clientes (Harvey, 1998). Essa estrutura ancora-se no sistema de informação que integra, em rede, tempos e processos diferentes, organizando o espaço global de fluxos de mercadorias e permitindo, dessa forma, a acumulação de capital por empresas parceiras no processo.

Nos últimos anos, nas ações governamentais e nas estratégias empresariais, observa-se uma revalorização do transporte de cargas por via fluvial. Dá-se importância à logística de transporte, adotando-se um novo modo de regulação de portos e de controle das vias navegáveis. Alguns rios passaram a ser valorizados, por estabelecerem uma ligação entre oceanos, do Pacífico ao Atlântico e ao Caribe. É o caso dos rios Huallaga, Marañón, Ucayali e Amazonas no Peru, Putumayo e Napo no Equador, Putumayo na Colômbia e Iça, Solimões e Amazonas no Brasil, que abarcam $6.000 \mathrm{~km}$ de vias navegáveis. Fala-se em modernização do transporte fluvial e aposta-se na compressão do tempo do transporte de cargas e na redução de custos, visando à competitividade da economia nacional.

A reestruturação produtiva e a flexibilização alteraram os fluxos de mercadorias, e houve também um aumento da produtividade, em decorrên- 
cia da melhoria de dispositivos organizacionais e institucionais que permitiram a adoção de outro modo de regulação do trabalho e de apropriação de qualidades da força de trabalho e da subjetividade dos trabalhadores (Boyer, 2006), com base em um novo regime de acumulação. Com a globallização, a economia de transporte é cada vez mais determinada por grandes empresas de armadores internacionais. Esses armadores (megacarriers) dominam as rotas mundiais (Leste-Oeste e Norte-Sul). No Brasil, as megacarrriers têm o controle do transporte de longo curso. Elas participam de uma rota na qual os armadores brasileiros funcionam conjuntamente com navios de bandeira estrangeira, atendendo a um mercado crescente e com lucros extraordinários (Agência Nacional..., 2011a).

Ao estudar a reestruturação produtiva na área portuária do Pará, Castro e Santos (2006, p.27) mostram, para o caso de Belém, as dimensões contraditórias entre as representações dominantes sobre a modernização, o poder de competitividade entre empresas e os efeitos sobre o campo do trabalho. A introdução de técnicas de modernização, como revelam as autoras, permitiu flexibilizar a gestão e o processo de trabalho, levando a grande redução dos postos de trabalho,apesar da expansão da atividade no Porto da Vila do Conde.

A estratégia de transporte por meio de contêiner possibilitou aos países exportadores uma situação confortável na estrutura de comércio. Inclui-se aí o caso brasileiro, que teve um extraordinário crescimento, segundo informa a Agência Nacional... (2011a, 2011b), de 20,57\% nesse setor, quatro vezes mais o alcançado em 1994. No sistema da Companhia das Docas do Pará, o movimento verificado quase triplicou o volume de contêineres de 1997 a 2010 (Agência Nacional... 2011b). O crescimento do volume de cargas transportadas por via marítima e fluvial foi possível graças à introdução de técnicas que permitiram aumentar a conectividade entre mercados, viabilizar as ligações entre local, regional e global e, consequentemente, reduzir preços.

As Figuras 1 e 2 mostram, de forma clara, os territórios para onde se dirigem os investimentos: ${ }^{5}$ as fronteiras políticas do Brasil, nos estados mais preservados, social e ambientalmente, da violência dos processos ocorridos na Amazônia Oriental e no Mato Grosso, dos anos 70 aos 90, sobretudo. Identificamos, na Amazônia, 41 projetos voltados para o setor transporte, dos quais 29 distribuídas pelos seguintes estados: 15 obras no Pará, 10 no Maranhão, 14 no Amazonas, 7 em Roraima, 11 em Tocantins, 12 em Amapá, 14 em Acre e 17 em Rondônia (Brasil. 2011, p.37).

Observam-se, ainda, corredores com conectividade de transporte, que são ligações intermodais, como a integração da BR-319 à hidrovia do rio Amazonas (porto de Manaus), a integração da BR-163 à hidrovia do rio Amazonas e à hidrovia Teles-Pires, a integração da BR230, Transamazônica, por meio da construção de uma ponte sobre o rio Araguaia, a integração da hidrovia do rio Amazonas, via BR-230, à hidrovia do rio Tocantins, além das ligações com a ferrovia Norte-Sul-Estrada de Ferro Carajás. Esses corredores estão previstos no contexto da malha nacional com sincronização de tempos, conforme as partes que compõem o sistema nacional de transporte. É importante destacar a comunicação entre o planejamento da IIRSA e a experiência brasileira na área de transporte, no sentido lato, para áreas de fronteira.

A região amazônica, nos diferentes países, tem uma tradição de transporte fluvial que remonta a milênios - para passageiros e cargas em embarcações de pequeno, médio e grande porte, construídas em estaleiros regionais com mão de obra local. No entanto, uma polêmica divide segmentos envolvidos nessa área de navegação fluvial a propósito da vontade política de modernizar os meios de transporte, substituindo a atual frota em madeira por transportes com base em ferro e

${ }^{5}$ Os recursos do PAC I para o transporte na região Norte sinalizam prioridades. Dos recursos alocados por modalidade de transporte, observa-se a seguinte distribuição: setor rodoviário com 60,32\%, o ferroviário com $23 \%$; o hidroviário 13,22\% e, finalmente, o aeroportuário, com $0,28 \%$ dos recursos. A integração modal e intermodal faz parte de uma certa concepção de planejamento estratégido planejamento voltado para a Amazônia (Brasil, 2011). 
Figura 1 e 2 - Mapas com obras de transporte rodoviário e ferroviário do PAC I e do PAC II, na Amazônia
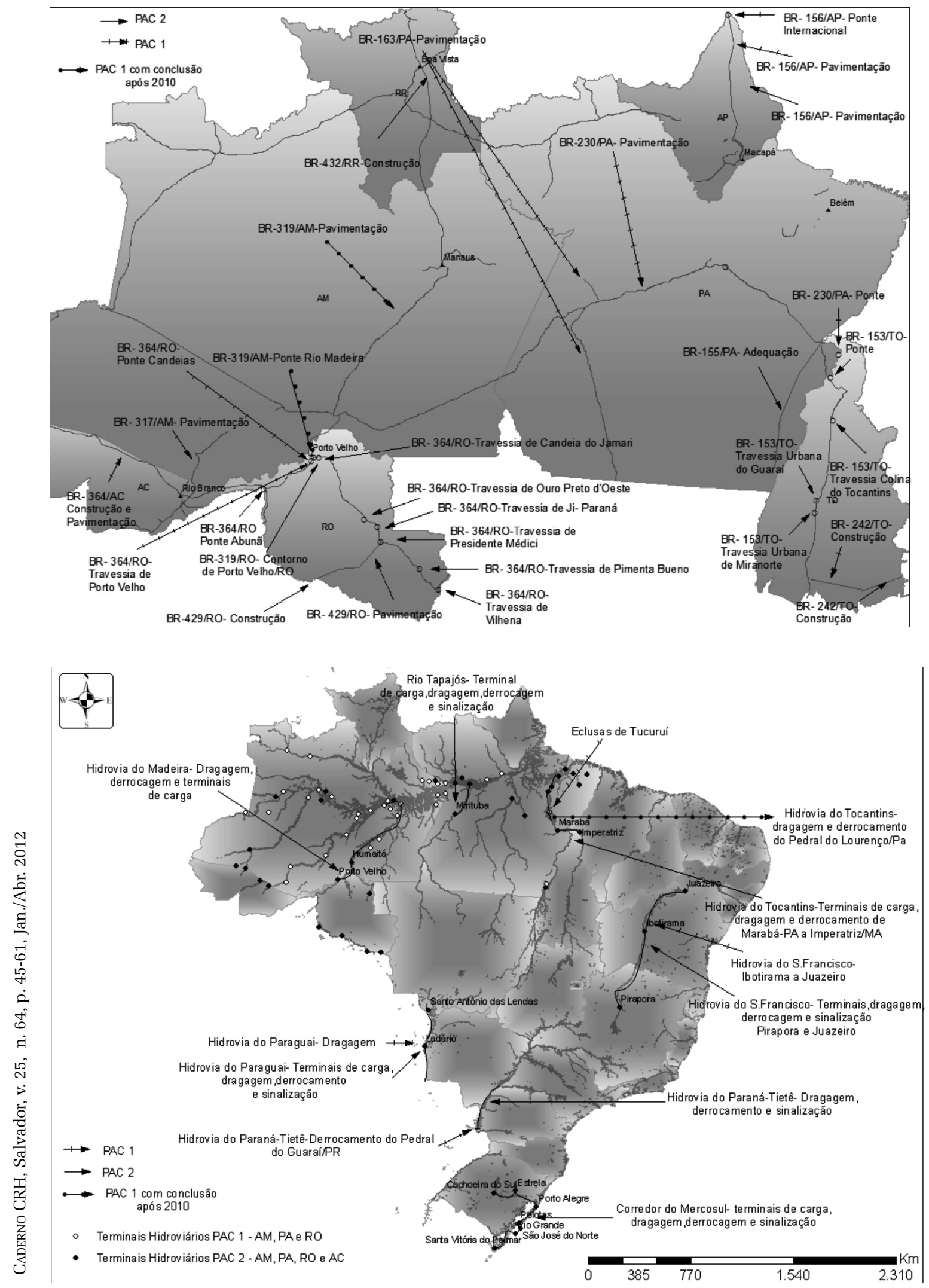
aço, mais rápidos e com capacidade para transportar maior quantidade de carga. As posições são divergentes: de um lado, as associações de construtores de barcos na Amazônia e de mestres tradicionais de carpintaria naval defendem a eficácia das embarcações tradicionais, testadas há séculos, com reduzida ocorrência de acidentes, comparativamente ao tamanho da frota, e com geração de trabalho e renda com base em conhecimentos locais, em toda a extensão da região; de outro, setores do mercado e da engenharia naval, representantes de federações da indústria, e inclusive a Marinha do Brasil, interessados em modernizar a frota, alegando que as embarcações de madeira são obsoletas, não oferecem segurança e não são condizentes com a modernização do setor. Cabe ressaltar que a frota existente percorre essa imensidão de cursos d'água cotidianamente e é produzida em centenas de estaleiros localizados nas áreas ribeirinhas da PanAmazônia. Certamente, a relação com o tempo está presente no confronto entre posições e estratégias, pois há temporalidades em conflito. A modernização do setor de transporte é defendida nas políticas setoriais articuladas ao sistema nacional de planejamento e à visão estratégica de futuro.

\section{AMAZÔNIA BRASILEIRA: modelo de produ- ção de commodities?}

A Amazônia foi transformada em uma fronteira de commodities. A expansão da pecuária brasileira ocorre na sua fronteira, com frentes peruanas, bolivianas e colombianas. A expansão dos plantios de grãos (arroz, milho e soja) e a exploração de madeira empurram as fronteiras até os seus limites nacionais. Por outro lado, o interesse pela mineração é bastante amplo, pois grande extensão da Amazônia tem jazidas minerais. ${ }^{6}$ A Amazônia tornou-se um mercado de produtos e insumos, li-

${ }^{6}$ Os minerais são de várias naturezas: minerais energéticos (carvão mineral, linhito, urânio), minerais metálicos (chumbo, cobre, cromo, estanho, ferro, manganês, molibdênio, nióbio, níquel, ouro, titânio, zinco), gemas (água-marinha, amazonita, ametista, diamante, esmeralda, granada, malaquita, opala, quartzo citrino, quartzo hialino, topázio, turmalina e produção de minerometalúrgicos siderúrgicos, entre outros. gado a redes internacionais altamente sofisticadas e a grandes empresas, como, por exemplo, a Petrobras, a Vale (do Rio Doce), a Andrade Gutierrez e a Cargill. Dos seis grupos de bens exportados pelo País - soja, carne, minérios, suco de laranja, petróleo e celulose em 2010 -, os três primeiros eram, majoritariamente, produzidos na Amazônia ${ }^{7}$ (Castro, 2010).

Embora o Brasil tenha diversificado, ao longo das últimas décadas, seu parque industrial e sua inserção no mercado mundial, ele não deixa de ser, por excelência, um produtor e exportador de commodities. A Amazônia contribui também para a produção de dois outros produtos do ranking nacional - celulose e petróleo (com gás natural) -, reafirmando a importância da exportação no cenário nacional. Por outro lado, a globalização e o aumento da competitividade têm provocado, no âmbito local, o acirramento das estratégias de apropriação de terras e de recursos por empresas nacionais e internacionais, tendo em vista investimentos imediatos ou reservas de nichos de mercado. Essas estratégias são responsáveis, em grande parte, pela concentração fundiária, pela grilagem, pela pistolagem, por conflitos em torno da terra e também pelo desmatamento acumulado (Castro, 2005, p.46; 2009, p.85). E se atualizam com o avanço para as últimas fronteiras nacionais.

A política que norteou o avanço da "fronteira econômica" organizou-se de forma a permitir a integração do mercado nacional às estruturas produtivas. Para os grupos que migraram em direção a essa mesma fronteira, como colonos atraídos por uma "política de integração", o apoio do Estado foi reduzido. Nesse contexto, os projetos de colonização estavam subordinados ao projeto mais amplo de modernização institucional e econômica do país. Justamente por isso, o governo federal priorizou políticas direcionadas à empresa agropecuária. Num

${ }^{7} \mathrm{Na}$ Amazônia, essas ações são "incentivadas e alimentadas pelos grupos sojeiros e minero-siderúrgicos (ao defenderem o asfaltamento das estradas e a implantação de projetos hidrelétricos) (grupos econômicos Amaggi, Bunge, Cargill, Vale), além de bancos (FMI, BID, Corporação Andina de Fomento, BNDES), como também grandes empreiteiras brasileiras - Odebrecht, Camargo Corrêa e Andrade Gutierrez - que, com seu enorme poder econômico, vêm exercendo o lobby à integração de infraestrutura física nacional e internacional" (Couto, 2008, p.81). 
primeiro momento, os investimentos vão para a pecuária, a exploração madeireira e a agricultura. O modelo desenhado pelo Instituto Nacional de Colonização e Reforma Agrária (INCRA) para certas áreas da Transamazônica e para a rodovia Cuiabá-Santarém previa grandes propriedades, e não por acaso surgiram as políticas destinadas a apoiar a empresa agropecuária. Igualmente, o Programa Polamazônia foi concebido como um programa de polos agropecuários, madeireiros e minerais, sendo projetados 15 polos no Pará. ${ }^{8}$ Em um segundo momento, no correr dos anos 80, predominam projetos de mineração e de infraestrutura energética, estradas e comunicação. Os investimentos foram direcionados para a produção mineral no âmbito do Programa Grande Carajás, inclusive para a construção das hidrelétricas de Tucuruí e Balbina. Nos anos 90, o Plano Brasil em Ação (19961999) e, logo após, o Avança Brasil (2000-2003), com os projetos de infraestrutura articulados em eixos de desenvolvimento, traçam as linhas de intervenção no espaço regional com base em projetos de infraestrutura de transporte e comunicação. No terceiro momento, abre-se a fronteira a empresas de mineração, de agricultura mecanizada, de madeira certificada. O PAC viria a consolidar um novo papel a ser dado à infraestrutura - energia, transporte, estradas, comunicação-, visando a criar estruturas de produção de energia, como as dezenas de hidrelétricas projetadas para os principais rios da Amazônia, sobretudo os afluentes das bacias do rio Amazonas e do Tocantins, e a intensificar a produção de commodities e seu escoamento para novos mercados.

Em que são diferentes esses momentos? Atualmente, estão em jogo grandes interesses de empresas, bancos, agências nacionais e internacionais

${ }^{8}$ A história econômica dessa região está marcada pela influência dos investimentos do Programa Polamazônia que, na década de 70, concedeu gordos subsídios públicos a empreendimentos privados nos setores voltados para a exportação: pecuária, madeira e mineração. Rondônia, Mato Grosso, Tocantins e sudeste e sudoeste do Pará são exemplos da ação de programas governamentais de colonização, de abertura de estradas, de mineração, energia e incentivos fiscais a médias e grandes empresas de pecuária e madeira, o que determinou o avanço de novas frentes econômicas com apropriação de imensos territórios da União. etc. e aportes financeiros públicos e privados com capacidade de impor seus interesses no espaço e no tempo. Por isso, levantamos a hipótese de que estamos diante de um grande investimento governamental que tende a provocar transformações para além da fronteira nacional.

\section{Expansão da fronteira de commodities: pecuá- ria e mineração}

Governos sul-americanos esperam desenvolver estratégias empresariais de ampliação da capacidade competitiva e adquirir melhores condições no mercado. Para ilustrar, examinaremos a pecuária e a mineração na Amazônia brasileira e refletiremos sobre os impactos sociais e ambientais que poderão ocorrer com a abertura de estradas e a constituição de corredores de escoamento para os principais mercados mundiais.

Todas as grandes regiões do Brasil são produtoras de gado. Em 2009, o Brasil possuía quase 75 milhões de cabeças bovinas (74.679.513). Por isso, a pressão sobre a disponibilidade de terras por parte da pecuária, no mercado de terras brasileiro, tem sido uma constante. O Sul e o Sudeste lideraram o setor, mas a pecuária cresceu em ritmo mais acelerado nas últimas décadas nas regiões Centro-Oeste (maior produtora, com 34\%) e Norte (com $20 \%$ ), o que corresponde ao total de $54 \%$ de participação no rebanho nacional. Porém as demais regiões têm ainda expressiva participação (46\%).

A expansão da pecuária no país foi possível graças ao avanço, nos últimos 50 anos, da fronteira agropecuária sobre a floresta amazônica e o cerrado mato-grossense. Contou, para tal, com financiamentos públicos diretos, concedidos por meio de incentivos fiscais e créditos bancários que privilegiaram os projetos de pecuária e a concessão de terras, e com os financiamentos indiretos, por meio da construção dos projetos de infraestrutura que garantiam a abertura de novas fronteiras. Isso explica por que mais de um terço do rebanho brasileiro está em terras da Amazônia Legal. Mato Grosso, Pará e Rondônia são os estados com maior participação-27.357.089, 16.856.561 
e 11.522.891 de cabeças, respectivamente (Tabela 1) etambém com maior taxa de desmatamento cumulativo no correr das últimas décadas, o que tem alterado profundamente a cobertura florestal e as formas tradicionais de ocupação do território. Daí a região ser palco de conflitos e violência.

A pecuária no Estado do Pará foi tradicionalmente praticada nas terras baixas da ilha do Marajó e do baixo Amazonas, conhecida como pecuária de várzea, padrão que foi, de longe, ultrapassado pela pecuária de terra firme e nas áreas de fronteira, no corredor das estradas abertas pela colonização e pelas madeireiras. Para se ter ideia da velocidade do crescimento da pecuária com a abertura da fronteira e as políticas estatais que favoreciam o seu financiamento público, ver os dados da Tabela 1. Em 1990, o Pará contava com um rebanho já expressivo de 4.599 .000 cabeças; em 1995, esse rebanho já ultrapassava seis milhões (6.080.000), chegando a quase 10 milhões (9.668.000) em 2000. Na década seguinte, ganharia mais velocidade o crescimento do rebanho; coincidentemente, houve aumento no volume de financiamento da pecuária na Amazônia, com vul- tosas somas sendo repassadas pelo Banco da Amazônia. O rebanho do Pará chega, em 2003, a 13.376.608 cabeças e, em 2005, a 18.063.669; em 2009, haveria uma queda conjuntural para 16.856.561 bovinos, embora o Estado continue a ser o segundo maior produtor do país. ${ }^{9}$

A mineração foi reconhecida pelo governo federal como um dos três pilares de sustentação do desenvolvimento do País (os outros são a agricultura e o turismo), pela diretriz do Plano Plurianual (PPA) 2004-2007 do governo federal e do relatório de junho de 2007 do Departamento Nacional de Produção Mineral do Ministério de Minas e Energia (DNMP). ${ }^{10}$ Nesses documentos, afirma-se que os indicadores de desempenho do Programa Mineração e Desenvolvimento Sustentável apontam resultados "excepcionais" da indústria extrativa mineral (inclusive petróleo e GNP) no período (Castro; Sousa; Golobovante, 2010, p.11).

Em 2007, a indústria da mineração e transformação mineral contribuiu com aproximadamente $5,17 \%$ do PIB Brasil (o que significa U\$S 70 bilhões), enquanto, na Amazônia, o setor participa com apenas $3 \%$ do PIB regional e gera, de for-

Tabela 1 - Rebanho bovino dos Estados da Amazônia Legal, 2001-2009 (cabeças, anos selecionados)

\begin{tabular}{|c|c|c|c|c|c|c|}
\hline & 2001 & 2003 & 2005 & 2006 & 2007 & 2009 \\
\hline Brasil & 176.388.726 & 195.551 .576 & 207.156.696 & 205.886.244 & 199.752.014 & 205.260.154 \\
\hline Amapá & 87.197 & 81.674 & 96.599 & 109.081 & 103.170 & 104.977 \\
\hline Amazonas & 863.736 & 1.121 .009 & 1.197 .171 & 1.243 .358 & 1.208 .652 & 1.350 .816 \\
\hline Mato Grosso & 19.921.615 & 24.613.718 & 26.651 .500 & 26.064.332 & 25.683.031 & 27.357.089 \\
\hline Pará & 11.046 .992 & 13.376.606 & 18.063.669 & 17.501 .678 & 15.353.989 & 16.856.561 \\
\hline Rondônia & 6.605 .034 & 9.392 .354 & 11.349 .452 & 11.484 .162 & 11.007 .613 & 11.532 .891 \\
\hline Amazônia Legal & 51.689.034 & 64.057 .475 & 74.589 .450 & 73.737 .986 & 70.158.241 & 74.679 .513 \\
\hline \multicolumn{7}{|c|}{ 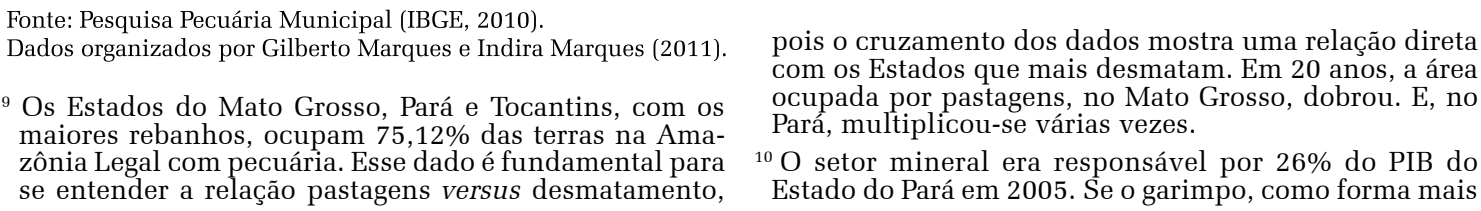 } \\
\hline
\end{tabular}


ma direta, menos de $2 \%$ dos empregos formais da região. Mas o setor responde por $40 \%$ do valor exportado pela Amazônia, e, no Pará e no Maranhão, os metais e minerais, com destaque para alumínio, ferro e aço, representavam mais de 70\% do valor exportado em 2006 (IMAZON, 2006).

Após o processo de privatização, a Vale tem ampliado sua lucratividade. Em 2002, seu lucro líquido atingiu um total de $\mathrm{R} \$ 2.043$ bilhões (dois bilhões e quarenta e três milhões de reais); em 2003, o lucro líquido ficou em $\mathrm{R} \$ 4.509$ bilhões (quatro bilhões e quinhentos e nove milhões de reais); em 2004, a empresa teve o maior lucro líquido em 62 anos de existência, totalizando R $\$ 6.460$ bilhões (seis bilhões e quatrocentos e sessenta milhões de reais), crescendo até atingir $\mathrm{R} \$ 21,3$ bilhões no ano de 2008. Apesar da redução para metade no ano de 2009, pois o setor foi fortemente afetado pela crise global, a empresa recuperou-se e mantém-se com lucros crescentes (Castro; Sousa; Golobovante, 2010, p.11). O crescimento anual da mineração no Pará é de 26\%, e a economia do setor mineral tem impactado positivamente a evolução do Produto Interno Bruto brasileiro (Sousa, 2011).

\section{MOBILIZAÇÕES COLETIVASNAPAN-AMAZÔNIA}

As análises dos processos de integração sulamericana têm sido apresentadas de forma lacunosa, pouco crítica e sem ligação com os reais processos de dominação. É possível perceber as diferenças entre o discurso dos planejadores e um projeto histórico de integração que recomponha as relações sociais e culturais, e não apenas econômicas. Lander (2005) considera que, preliminarmente, é necessário perguntar Para quem servirá a integração? Para os setores privilegiados das sociedades, para o capital, seja ele nacional ou transnacional, que poderá mover-se livremente no continente? Ou, ao con-

rudimentar de exploração mineral, ainda resiste, a produção atual é dominada por mineradoras que utilizam processo intensivo de tecnologia e robotização nas explorações. Os próximos investimentos previstos até 2012 em novos projetos e na expansão dos atuais, somam U\$S 17 milhões. Desse total, 97\% serão efetivados pela Vale, a maior parte deles na região sudeste do Pará, que responderá pela maior fatia $(86 \%)$. trário, haveria uma integração para todos que vivem nos países envolvidos, superando as contradições do capital e a tendência histórica de exclusão? (Lander, 2005). Tudo dependeria do modelo de integração em questão e da maneira como ele se “adaptaria” à lógica dominante de integração de blocos econômicos e de regulação da economia? O projeto de integração contempla espaços de autonomia e soberania e formula políticas públicas condizentes com as demandas da sociedade, com os territórios coletivos e com o desenvolvimento de seus processos produtivos, conforme perguntam os movimentos sociais indígenas na Bolívia?

Os movimentos sociais de várias nacionalidades são exemplos de formas de sociabilidade e de integração que existem nas fronteiras entre Brasil, Peru, Colômbia, Bolívia e Equador, que compõem a grande faixa fronteiriça da Amazônia Ocidental, ou nas fronteiras com países do Caribe, Venezuela, Suriname, Guiana, Brasil, Guiana Francesa, já na da Amazônia Oriental. Os temas em discussão nesses fóruns são variados, mas, nos últimos anos, intensificou-se a discussão sobre o território, as modalidades de afirmação de territorialidades e de defesa de processos de trabalho. Alguns fragmentos mostram a diversidade desses temas e seus impactos locais: como enfrentar os resultados do avanço de empresas brasileiras e do consequente desmatamento que ocorre no leste do Peru, a exploração madeireira que avança em direção da Bolívia, os arrozeiros e garimpeiros brasileiros na fronteira com a Venezuela, ou os problemas apresentados pelos grupos indígenas brasileiros na fronteira com a Guiana, ou ainda pelos garimpeiros no rio Oiapoque, em conflito com a Gendarmerie francesa?

Há um desconhecimento completo das experiências sociais e do campo de trocas, materiais e simbólicas que marcam as relações e conformam a vida social e as relações com a natureza nessas regiões. Nesse quadro da fronteira, há movimentos migratórios mais ou menos intensos, que envolvem migração de trabalho, mas também fazem parte das formas de sociabilidade entre povos que coabitam esses territórios, alguns milenarmente, 
independementemente de serem unidades nacionais diferentes. São identidades e territorialidades em jogo, espaço de trânsito de culturas e etnias pouco percebidas na superficialidade das interpretações sobre as fronteiras. A fronteira é um espaço complexo, com muitos atores sociais e étnicos e agentes econômicos, redes de comércio, migrantes que chegam com interesses diversos e veem aí um espaço também de oportunidades e de negócios.

\section{CONCLUSÃO}

Procuramos sustentar a ideia de que as macropolíticas nacionais atuais, voltadas para a Amazônia brasileira, ampliam sua abrangência territorial. A Pan-Amazônia torna-se um espaço de repercussão das dinâmicas nacionais, da intervenção de megaprojetos que acabam por desestruturar uma dada ordem social e ambiental existente e disponibilizar, assim, novas fronteiras de terras e recursos naturais.

OEstado tem optado pela solução mais tradicional de desenvolvimento - o que se tem revelado ineficaz social e ambientalmente -, que é a construção de grandes obras de infraestrutura, usando argumentos que supervalorizam os benefícios do desenvolvimento. São obras localizadas no território brasileiro e nas áreas amazônicas de países vizinhos, por intermédio da IIRSA. Produtos como minério, madeira, gado e pescado, na Amazônia, continuam a sair para o mercado por cadeias curtas e com reduzido padrão tecnológico.

Os projetos de grande escala, como as hidrelétricas em construção no Brasil, no Peru e na Bolívia, ou as estradas, ferrovias e portos apresentados pelos governos como obras para o desenvolvimento e a integração nacional e sul-americana, são densos em investimento e, por isso, representam um modelo de intervenção no território, não apenas do Estado, mas também de grandes empresas, nacionais e internacionais. Chesnais (1996) mostra que a internacionalização é dominada mais pelo investimento internacional do que pelo comércio exterior, e, portanto, molda as estruturas que predominam na produção e no intercâmbio de bens e serviços, com forte interação com as instituições bancárias e financeiras que definem as aquisições e as fusões. Esses grandes projetos, construídos para oferecer ao mercado os recursos naturais, são entregues a grandes empresas, nacionais e estrangeiras, que se localizam, via de regra, em territórios ocupados, mas se impõem à população local como prioridade nacional.

Além disso, os projetos dos PAC I e II aumentaram a desterritorialização de povos tradicionais na Amazônia brasileira e têm manipulado identidades pelo esvaziamento de sentidos, trazendo esses grupos para o contexto de suas representações sobre a modernização e o processo cilizatório. Têm reproduzido, assim, de forma recorrente e célere, formas de estigmatização, no sentido entendido por Goffman (1982) e de Elias (1994). Esses projetos têm sido motivo de contestações que dividem a sociedade brasileira, motivo de tensões e conflitos, embora se proponham a reduzir as desigualdades sociais e a diminuir a fragmentação interna, abordando temas como segurança alimentar, patenteamento de conhecimentos tradicionais, titulação de territórios de identidade, reforma agrária e soberania nacional.

Finalmente, a Amazônia, vista no cenário nacional e internacional, sobretudo, pelo aumento das taxas de desmatamento e pelo acirramento dos conflitos socioterritoriais, localiza-se em uma outra configuração geopolítica. Os olhos voltam-se para a Pan-Amazônia, imensa região e a última mais preservada do planeta. Imensa fronteira de recursos, integrada pelas culturas e etnias que milenarmente aí vivem e produzem suas existências, mas agora ameaçadas pelos programas neocoloniais que refazem discursos e prioridades e por estratégias geopolíticas de dominação das fronteiras. O conhecimento e a demonstração desses processos de dominação e dos efeitos que produzem passam a ser prioridade política das sociedades amazônicas e nacionais.

Recebido para publicação em 3 de novembro de 2011 Aceito em 5 de fevereiro de 2012 


\section{REFERÊNCIAS}

AGÊNCIA NACIONAL DE TRANSPORTES AQUAVIÁRIOS. Disponível em: www.antaq.gov.br/ Portal/ default.asp?. Acesso em: 6 out. 2011a.

. Disponível em: www.antaq.gov.br/Portal/pdf/Panorama Aquaviarios.pdf. Acesso em: 6 out. 2011b.

BOURDIEU, Pierre. A representação política: elementos para uma teoria do campo político. In:

lico. Rio de Janeiro: Difel, 1989. cap.7. O poder simbó-

BOYER, Robert. L'économie des conventions 15 ans après: un point de vue à partir de la théorie de la régulation. In EYMARD-DUVERNAY, François (Dir.) L'économie des conventions: méthodes et résultats. Paris: La Découverte, 2006. Tome II. p.45-66.

BRASIL. Ministério do Planejamento, Orçamento e Ges tão. Secretaria de Planejamento e Investimentos Estratégicos. Estudo da Dimensão Territorial para o Planejamento. v. 1, Sumário Executivo. Brasília, 2008a. 85 p.

. Ministério do Planejamento, Orçamento e Ges tão. Secretaria de Planejamento e Investimentos Estratégicos. Estudo da Dimensão Territorial para o Planejamento. v. 2, Visão estratégica nacional. Brasília, 2008b. 185 p.

Presidência da República. Programa de Aceleração do Crescimento. Relatórios. Brasília, 2011.

CARVALHO, José Guilherme; ALMEIDA, Alfredo Wagner B. (Org.). O Plano IIRSA na visão da sociedade civil da PanAmazônia. Belém: MPEG, 2009. p.76-97.

CASTRO, Edna. Estado e políticas públicas na Amazônia em face da globalização e da integração de mercados. In COELHO, Maria Célia Nunes; MATHIS, Armin; CASTRO Edna; HURTIENNE, Thomas (Org.) Estado e políticas públicas na Amazônia: gestão do desenvolvimento regional. Belém: Cejup, 2004. p.51-69.

Dinâmica socioeconômica e desmatamento na Amazônia. Novos Cadernos NAEA, Belém, v.2, n.1, p.539, 2005.

Território, biodiversidade e saberes de populacões tradicionais In: ; PINTON, F. Faces do trópico úmido: conceitos e novas questões sobre desenvolvimento e meio ambiente. Belém-São Paulo: Cejup, 1997 p.101-123

. Intregração sul-americana da IIRSA: visão do Es e dos atores da Pan-Amazônia. In: CARVALHO, José Guilherme; ALMEIDA, Alfredo Wagner B. (Org.) O Plano IIRSA na visão da sociedade civil da Pan-Amazônia. Belém: MPEG, 2009. p.76-97.

A Amazônia e seu lugar central na integraç̃a sul-americana. In: NASCIMENTO, Durbens Martins. Internacionalização e defesa nacional. Belém: UFPA, 2010 v.1, p. 21-45
; SANTOS, Maria Antonieta. Belém de águas e de portos: ação do Estado e modernização na superfície. In: Belem de águas e ithas. Belém: Cejup, 2006. p. 25-43.

SOUSA, Raimundo Valdomiro de; GOLOBOVANTE, Maria da Conceição; SILVA, Joelle Katiusia. Ações do Estado e estratégias empresariais do setor mineral para viabilizar a construção de novas usinas hidrelétricas na Amazônia. In: ENCONTRO LATINOAMERICANO DE CIENCIAS E BARRAGENS, 3, 2010. Anais... Belém, dez. 2010.

CHESNAIS, François. A mundialização do capital. Trad. Silvana Finzi. São Paulo: Xamã, 1996.

COUTO, Alessandro Biazzi. A atuação das grandes empreiteiras brasileiras na integração de infraestrutura na América do Sul. In: VERDUM, Ricardo (Org.) Financiamento e megaprojetos: uma interpretação da dinâmica regional sul-americana. Brasília, DF: INESC, 2008. p.79-88.

ELIAS, Norbert. O processo civilizador. Rio de Janeiro: Zahar, 1994. v.1.

GOFFMAN, Erving. Estigma: notas sobre a manipulação da identidade deteriorada. Rio de Janeiro: Zahar, 1982.

GUIMARÃES, Samuel Pinheiro. O mundo multipolar e a integração sul-americana. Disponível em: www.cebela.org.br/ Acesso em: 25 jul. 2008

HARVEY, David. A condição pós-moderna. São Paulo: Loyola, 1998.

IIRSA. Iniciativa para a Integração da Infraestrutura Regional Sul-Americana. Planejamento Territorial Indicativo. Brasília, DF: 2004 set.2011.

Documento base para discussão. Brasília, DF: 29

INSTITUTO DO HOMEM E MEIO AMBIENTE DA AMAZONIA. O avanco da fronteira na Amazônia: do boom ao colapso. Belém: 2006.

LANDER, Edgardo. Modelos alternativos de integração: projetos neoliberais e resistências populares. São Paulo: Rede REBRIT, 2005.

MARQUES, Gilberto; MARQUES, Indira. Agropecuária paraense, políticas públicas e tensões socioambientais. Belém: UFPA, 2011. Mimeo.

SOUSA, Raimundo Valdomiro. A influência do Estado no crescimento da economia do setor mineral e da CVRD de 1942 a 2010. 2011. Tese (Doutorado em curso) - Programa de Pós-Graduacão em Desenvolvimento Sustentável do Trópico Úmido, Núcleo de Altos Estudos Amazônicos, Universidade Federal do Pará. Belém: 2011. 


\section{BORDER EXPANSION, SOUTH AMERICAN INFRASTRUCTURE AND INTEGRATION MEGAPROJECTS}

\author{
Edna Castro
}

The analysis of the relationship between developmentalist policies and social and territorial dynamics in the Amazon usually focuses on a Brazilian national perspective. This article aims to reveal an increase of interest in the exploitation of the region's natural resources, beyond its political borders, thus turning the Pan-Amazon into a vital zone in Brazilian geopolitics. The Brazilian Growth Acceleration Programs (PAC I and II) and the Initiative for the Integration of the Regional Infrastructure of South America (IIRSA) follow the same direction of a competitive integration, adopting a modernization model based on investment megaprojects. The IIRSA, carried on in South America as a regional block, and the PAC, developed nationwide, are programs that aim to boost transport, energy and communication logistics. Continent-wise, they both indicate irreversible social and territorial dynamics and represent the common interests of Brazil and the other countries, based on the 1970's dominant model of border expansion in the Amazon.

KEY-WORDS: border, state policies, integration, megaprojects, Pan-Amazon.

\section{EXPANSION DES FRONTIÈRES, GRANDS PROJETS D'INFRASTRUCTURE ET INTÉGRATION SUD-AMÉRICAINE}

\author{
Edna Castro
}

Les analyses de la relation entre politiques de développement et dynamiques socio-territoriales en Amazonie s'intéressent de plus en plus à leur dimension nationale. Cet article cherche à révéler l'intérêt accru pour l'exploitation des ressources naturelles de la région, au-delà de leurs frontières politiques, ce qui fait que la Pan-Amazonie est devenue un espace central de la géopolitique brésilienne. Les Plans pour l'Accélération de l'Économie (PAC I et II) et l' IIRSA vont dans le même sens, celui d'une intégration compétitive qui adopte un modèle de modernisation basé sur des mega-projets d'investissements. L'IIRSA, en tant que bloc régional dans le cadre de l'Amérique du Sud, et le PAC, dans le cadre national, sont des programmes tournés vers la logistique des transports, de l'énergie et de la communication. Sur le plan continental, ils sont l'expression de dynamiques socio-territoriales irréversibles et représentent des intérêts communs pour le Brésil et les autres pays par le biais du modèle dominant d'expansion de la frontière amazonienne à partir des années 70 du siècle dernier.

MoTS-CLÉS: frontière, politiques d'état, intégration, grands projets, Pan-Amazonie.

Edna Castro - Socióloga do Núcleo de Altos Estudos Amazônicos, da Universidade Federal do Pará - UFPA. Doutora em Sociologia pela École des Hautes Études en Sciences Sociales. Pós-doutora pelo Centre National de la Recherche Scientifique. Professora da UFPA. Pesquisadora do CNPq. Professora Visitante da Université de Québec à Montreal Departamento de Sociologia, Canadá; da Universidade de Brasília, UnB, Departamento de Sociologia e da Université Le Havre, França. Diretora do Núcleo de Altos Estudos Amazônicos - NAEA/ UFPA - entre 2004 e 2008. Foi Presidente da Associação Nacional de Pós-Graduação e Pesquisa em Planejamento Urbano e Regional ANPUR, gestão 2007-2009 e exerceu função de Diretora na Associação Nacional de Pós-Graduação em Sociologia - ANPOCS nos períodos (1986-1988 e 1994-1996), da Sociedade Brasileira de Sociologia - SBS (2009-2011). Atualmente é diretora da Sociedade Brasileira para o Progresso da Ciência - SBPC. Tem pesquisas e publicações nos temas: trabalho, políticas públicas, cidades, identidades e territorialidades de grupos tradicionais e conflitos sociais e ambientais, Amazônia, Pan-Amazônia, América Latina. 
